\title{
Proteomic Analysis of Potato Responding to the Invasion of Ralstonia solanacearum UW551 and Its Type III Secretion System Mutant
}

\author{
Bingsen Wang, ${ }^{1,2}$ Tianjiu He, ${ }^{3}$ Xueao Zheng, ${ }^{1,2}$ Botao Song, ${ }^{1,2}$ and Huilan Chen ${ }^{1,2,+}$ \\ ${ }^{1}$ Key Laboratory of Potato Biology and Biotechnology, Ministry of Agriculture and Rural Affairs, Huazhong Agricultural \\ University, Wuhan 430070, China \\ ${ }^{2}$ Key Laboratory of Horticultural Plant Biology, Ministry of Education, Huazhong Agricultural University, Wuhan, 430070, China \\ ${ }^{3}$ Guizhou Institute of Biotechnology, Guizhou Academy of Agricultural Sciences, Guizhou Province, Guiyang 550006, China
}

Accepted 17 December 2020.

\begin{abstract}
The infection of potato with Ralstonia solanacearum UW551 gives rise to bacterial wilt disease via colonization of roots. The type III secretion system (T3SS) is a determinant factor for the pathogenicity of $R$. solanacearum. To fully understand perturbations in potato by $R$. solanacearum type III effectors(T3Es), we used proteomics to measure differences in potato root protein abundance after inoculation with $R$. solanacearum UW551 and the T3SS mutant (UW551 $\triangle H r c$ V). We identified 21 differentially accumulated proteins. Compared with inoculation with UW551 $\triangle H r c \mathrm{~V}, 10$ proteins showed significantly lower abundance in potato roots after inoculation with UW551, indicating that those proteins were significantly downregulated by T3Es during the invasion. To identify their functions in immunity, we silenced those genes in Nicotiana benthamiana and tested the resistance of the silenced plants to the pathogen. Results showed that miraculin, HBP2, and TOM20 contribute to immunity to $R$. solanacearum. In contrast, PP1 contributes to susceptibility. Notably, none of four downregulated proteins (HBP2, PP1, HSP22, and TOM20) were downregulated at the transcriptional level, suggesting that they were significantly downregulated at the posttranscriptional level. We further coexpressed those four proteins with 33 core T3Es. To our surprise, multiple effectors were able to significantly decrease the studied protein abundances. In conclusion, our data showed that T3Es of $R$. solanacearum could subvert potato root immune-related proteins in a redundant manner.
\end{abstract}

Keywords: genomics, metabolomics, potato, proteomics, Ralstonia solanacearum, resistance, T3Es, type 3 secretion

B. Wang and T. He contributed equally to this work.

${ }^{\dagger}$ Corresponding author: H. Chen; chenhuilan@mail.hzau.edu.cn

Funding: This work was funded by the National Natural Science Foundation of China grant 31871686 and the Independent Innovation Project of Guizhou Academy of Agricultural Sciences grant No. (2014)015.

*The $\boldsymbol{e}$-Xtra logo stands for "electronic extra" and indicates that supplementary materials and supplementary tables are published online.

The author(s) declare no conflict of interest.

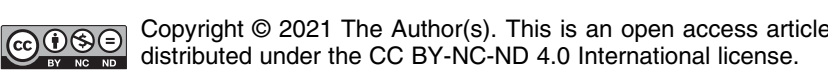

Potato (Solanum tuberosum L.) is one of the most important food and economic crops worldwide. Potato bacterial wilt, caused by Ralstonia solanacearum, is one of the most destructive bacterial diseases (Mansfield et al. 2012) and limits potato production worldwide (Champoiseau et al. 2009; Elphinstone 2005). $R$. solanacearum is a soilborne pathogen that invades its host by entering the roots (Genin 2010), and rapidly colonizes the xylem vessels (Digonnet et al. 2012). Large amounts of exopolysaccharides (EPS) are produced in the xylem vessels that stop the flow of water, which leads to wilting and, eventually, the death of plants (Garg et al. 2000; Genin and Denny 2012). In roots, EPS distribution in vascular tissues of susceptible varieties is more extensive than that of resistant varieties at 5 days after inoculation (McGarvey et al. 1999), suggesting that the root system may limit bacterial colonization.

Bacterial wilt is difficult to control due to the pathogen aggressiveness and lack of resistance in commercial potato varieties (Coll and Valls 2013; Puigvert et al. 2017). Resistant plants can delay colonization by the pathogens in the root vascular system (Caldwell et al. 2017); however, the mechanism underlying this phenomenon is not clear.

As with most Gram-negative pathogens, the type III secretion system (T3SS) is the main determinant of $R$. solanacearum pathogenesis (Boucher et al. 1985, 1987), because it enables the pathogen to inject virulence factors, called type III effectors (T3Es), directly into host cells, thereby disabling host defenses and causing disease (Brito et al. 2002; Büttner 2016). $h r c \mathrm{~V}$ is one of the T3SS structural genes, and its mutant is not toxic to plants (Lonjon et al. 2016). hrc V mutant strains can infect plant roots naturally but the bacteria can only colonize the roots and cannot spread (Vasse et al. 2000).

When approaching plant cells, conserved bacterial molecules (pathogen-related molecular model) may be sensed by receptors on the surface of plant cells, triggering activation of the plant immune system (Darvill and Albersheim 1984). This is called pathogen-associated molecular pattern (PAMP)-triggered immunity (PTI), which can limit bacterial growth and prevents the development of disease (Chisholm et al. 2006). There have been many reports about the inhibition of plant PTI by pathogen effectors. For example, $16 R$. solanacearum T3Es have been reported as inhibitors of flg22-induced reactive oxygen species (ROS) production, which is a typical PTI-related marker (Landry et al. 2020). Studies have shown that ROS are involved in the interaction between roots and pathogens (Jamet et al. 2003). When plants are invaded by pathogens, they produce ROS (Imlay 2008; Joo et al. 2001; Mori and Schroeder 
2004) by a process known as oxidative burst (Cao et al. 2012). During colonization, $R$. solanacearum produces an oxidative stress response as an adaptation to the ROS produced by the host (Brown and Allen 2004; Flores-Cruz and Allen 2009). ROS are mainly produced by cell-wall-bound peroxidases and NADPH oxidases (Torres and Dangl 2005), and they represent the main method used by plants to initially resist pathogen invasion (Bolwell 1999; Miller and Britigan 1997). Effectortriggered immunity (ETI) is an accelerated and amplified PTI response that leads to disease resistance and usually produces a hypersensitive cell death reaction at the infected site (Jones and Dangl 2006). Resistant plants have evolved a mechanism for detecting such bacterial perniciousness through a family of polymorphic intracellular nucleotide-binding leucine-richrepeat (NB-LRR) receptors (Cui et al. 2015; Jacob et al. 2013). During infection, a given effector is "specifically recognized" by one of the NB-LRR proteins, causing ETI, which effectively prevents pathogen multiplication (Chiang and Coaker 2015). Natural selection drives pathogens to avoid ETI by shedding or diversifying the identified effector, or by acquiring more effectors to suppress ETI (Macho 2016). Although the suppression of PTI by T3Es has been widely documented (Landry et al. 2020), reports about T3Es that suppress ETI might vary substantially among different host species, as well as between host species with unknown targets.

Because the root is the first line of defense against invasion by $R$. solanacearum, exploring root colonization by pathogens is key to understanding plant resistance against infection (McAvoy et al. 2012). Proteomics is a powerful tool with which to study host-pathogen interactions and consider the underlying mechanisms of disease, basic defense, and gene resistance as a whole. Isobaric tags for relative and absolute quantitation (iTRAQ) is an isobaric labeling method used in quantitative proteomics (Ross et al. 2004). This is one of the newest techniques used for the quantitative study of gene expression at the proteome level and it can detect low-abundance proteins in complex samples (Gafken and Lampe 2006).

In this work, we aimed to screen differentially accumulated proteins after inoculation with $R$. solanacearum UW551 and the T3SS mutant by iTRAQ and examine their relationship with plant immunity. We found that bacterial colonization and multiplication differed among roots inoculated with the wildtype (WT) $R$. solanacearum strain and those inoculated with its T3SS mutant strain. This led us to confirm that the presence or absence of effectors would make a difference in responses. We then performed a proteomic analysis of plant roots inoculated with $R$. solanacearum using the iTRAQ approach and identified 21 differentially accumulated proteins (DAPs). Using the virus-induced gene silencing (VIGS) system, four proteomicsidentified proteins were preliminarily confirmed to be involved in plant defense. Four downregulated proteins had no change on the transcriptional level. Then, we coexpressed the four proteins with 33 core T3Es and found that the abundance of these proteins significantly decreased when expressed with multiple effectors. Our data suggest that the downregulation of proteins is directly related to the presence of T3Es, and the existence of multiple downregulated proteins is also related to plant defense response.

\section{RESULTS}

Roots colonization of the $R$. solanacearum UW551 T3SS mutant is limited in the susceptible potato $\mathrm{C} 9701$.

Pathogenicity assays of the $R$. solanacearum UW551 WT and $h r c \mathrm{~V}$ deletion mutant were performed on a susceptible potato accession, C9701 (Chen et al. 2013). A functional T3SS was required to cause disease in the susceptible potato (Figs.
1A; Supplementary Fig. S1). To observe the infection process, in vitro potato plants were root inoculated with the $R$. solanacearum reporter strains UW551::GUS and UW551 $\triangle H r c \mathrm{~V}:$ :GUS. Bacteria were detected in plants from 2 to 7 days postinoculation (Fig. 1B). Three experiments were performed using three to five replicate plants that were arranged in a completely randomized design. The UW551 strain displayed a stronger $R$. solanacearum $\beta$-glucuronidase (GUS) signal in the roots than the $h r c \mathrm{~V}$ mutant did (Fig. 1B). The GUS signal of the $h r c \mathrm{~V}$ mutant strain was only present in the roots, and its range of colonization was smaller than that of the UW551 strain in the plant as a whole.

To further confirm the differences in root bacterial colonization levels, root samples from plants inoculated with either strain were used for quantitative analysis of pathogen colonization by plate counting. The results showed that the $R$. solanacearum WT proliferated abundantly in the roots, rapidly increasing to $1 \times 10^{6} \mathrm{CFU} / \mathrm{g}$ on the third day of inoculation and reaching more than $1 \times 10^{9} \mathrm{CFU} / \mathrm{g}$ after 7 days of inoculation (Fig. 1C). In contrast, the concentration of the $h r c \mathrm{~V}$ mutant showed no apparent increase after infection. These data showed that the potato roots could limit the T3SS mutant strain colonization of the whole plants but not that of the WT strain.

\section{iTRAQ protein profiling.}

Because of the phenotypic differences observed in the differentially infected roots, we compared the root tissue proteomes of potato plants infected with the $R$. solanacearum WT strain and those infected with the T3SS mutant strain. Because the bacterial quantification in the root showed that the $R$. solanacearum UW551 population was significantly higher than the T3SS mutant strain at day 7 after inoculation, root samples were collected at 6 days postinoculation and proteomic analysis was performed using iTRAQ. In total, 2,830 original proteins and 2,424 trusted proteins were obtained (at least one unique peptide with high confidence) and identified by iTRAQ analysis against the Uniprot database Solanum tuberosum.

All proteins were annotated to 38 gene ontology (GO) terms by GO analysis (Fig. 2; Supplementary Table S4). In terms of biological process categories, most proteins were categorized into the metabolic process $(671,28.7 \%)$, cellular process $(802$, $34.3 \%)$, and response to stimulus $(169,7.2 \%)$. The major cellular components were cell $(999,42.7 \%)$, cell part (999, $42.7 \%)$, and organelle $(611,26.1 \%)$. The largest molecular functions of proteins obtained by GO analysis were catalytic activity $(709,30.3 \%)$ and binding $(441,18.1 \%)$.

\section{Comparative potato root proteomic analysis identified 21 proteins with significant differential abundance between infection with the $R$. solanacearum WT and the T3SS mutant.}

Proteins displaying a fold change $>1.40$ or $<0.71$ in relative abundance and a $P$ value $<0.05$ were considered DAPs. We identified 10 DAPs with significantly lower abundance in potato inoculated with the WT UW551 strain and 11 proteins with significantly higher abundance in potato inoculated with the WT UW551 strain (Table 1). A pie chart of a PANTHER classification analysis with associated GO terms for the 21 DAPs is shown in Figure 3. In terms of biological process categories, most proteins were categorized into the metabolic process $(1,16.7 \%)$, cellular process $(3,50 \%)$, and response to stimulus $(2,33.3 \%)$. The major cellular components were cell $(5,41.7 \%)$, cell part $(5,41.7 \%)$, organelle $(1,8.3 \%)$, and protein-containing complex $(1,8.3 \%)$. The largest molecular functions of proteins obtained by $\mathrm{GO}$ analysis were catalytic activity $(4,50 \%)$, translation regulator activity $(1,12.5 \%)$, and binding $(3,37.5 \%)$. 

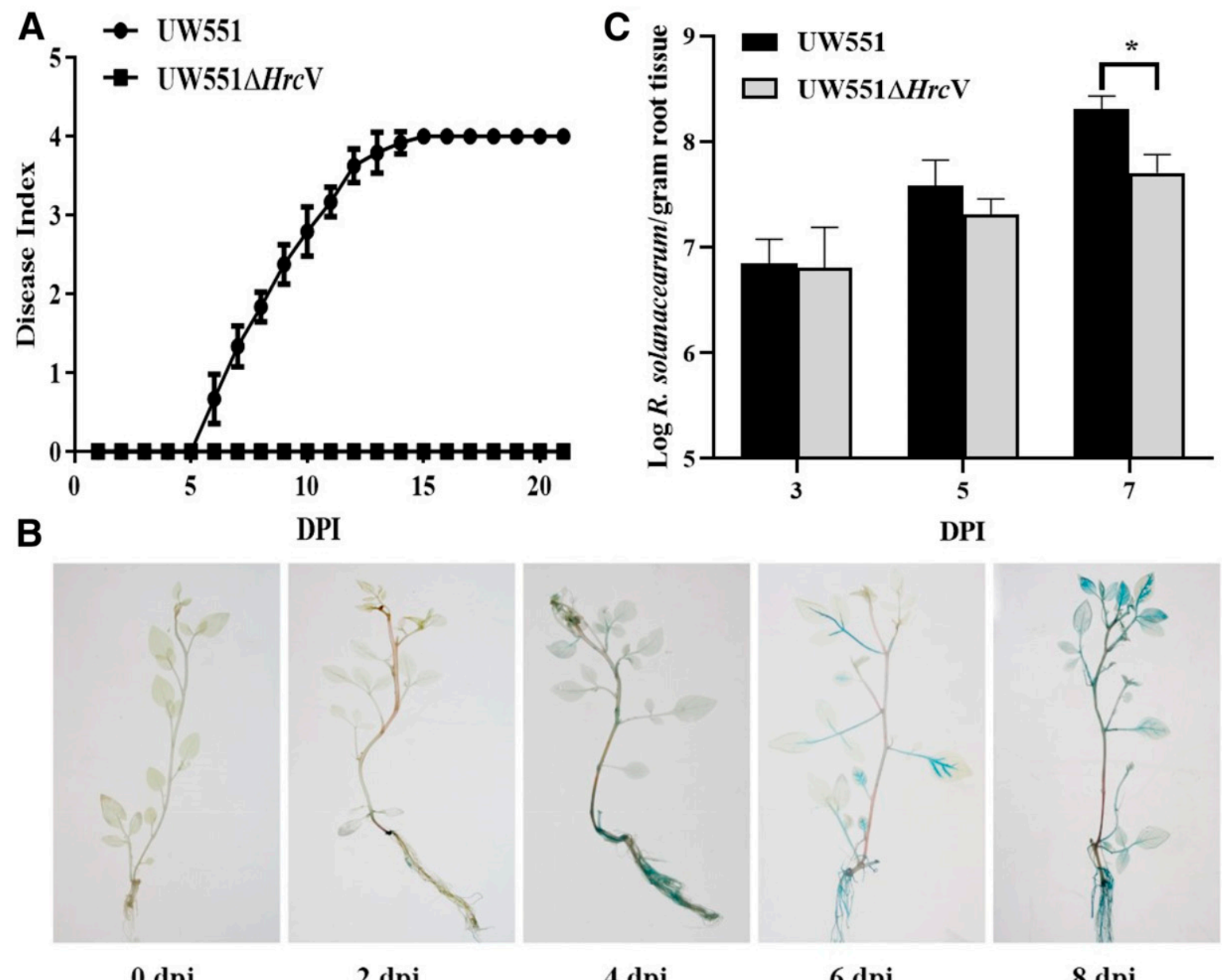

DPI

0 dpi

2 dpi

4 dpi

6 dpi

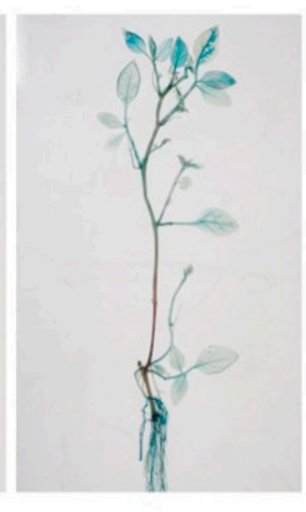

UW551::GUS

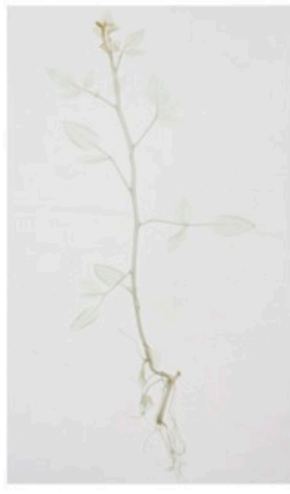

0 dpi

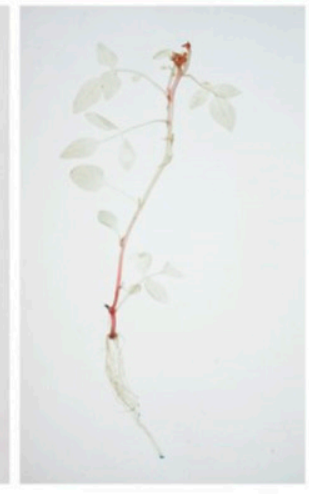

2 dpi

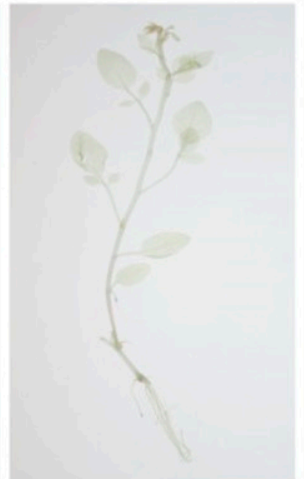

4 dpi

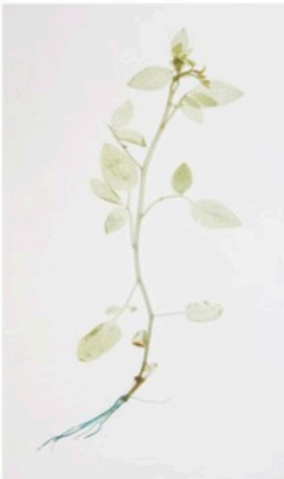

6 dpi

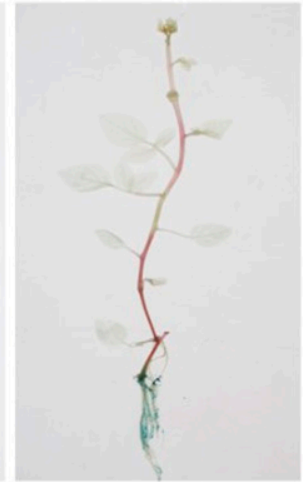

8 dpi

\section{UW551 $\triangle h r c \mathrm{~V}:: G U S$}

Fig. 1. The type III secretion system (T3SS) is necessary for full virulence of Ralstonia solanacearum in potato. A, Potato plants were inoculated by soil drench with the wild-type (WT) UW551 strain and its T3SS mutant. Cultured $R$. solanacearum was prepared to an optical density at 600 nm $=0.1$ and inoculated with $5.0 \mathrm{ml}$ of $R$. solanacearum suspension in each potato pot. Disease severity was rated from 0 to 21 days using a disease index scale. Data correspond to one representative experiment and each experiment included five plants per treatment. Error bars represent standard errors and DPI $=$ days postinoculation. B, Visualization of the tissue expression of $R$. solanacearum. Potato plants were inoculated with the WT UW551 strain or its T3SS mutant harboring the $\beta$-glucuronidase (GUS) protein under the control of the constitutive psbA promoter. In vitro potato plants (Solanum chacoense accession C9701) were harvested from 0 to 8 days postinoculation (dpi) and stained with GUS. C, In vitro bacterial populations of potato roots 3 , 5 , and 7 dpi inoculated with the WT UW551 strain or the T3SS mutant strain. Data correspond to one representative experiment and each experiment included four plants per treatment. Error bars represent standard errors and an asterisk $(*)=P<0.05$ with the Holm-Sidak method. 
The silencing of genes encoding the downregulated proteins by VIGS altered the susceptibility of Nicotiana benthamiana to $R$. solanacearum.

To verify whether the 10 downregulated proteins identified in potato were associated with the susceptibility of the plants to $R$. solanacearum infection, we employed VIGS, an approach frequently used in functional genomic studies in the family Solanaceae. Because it is difficult to silence these genes in potato, we instead silenced the homologous genes in the model plant Nicotiana benthamiana (Table 2).

The relative gene expression for the $N$. benthamiana homologous genes before silencing is listed in Table 2. The homologous genes were selected based on the highest sequence similarity to potato genes identified but considering the existence of other homologous genes with high sequence similarity $(>80 \%)$. The selected silenced regions are mainly conserved regions; thus, multiple homologous genes can be silenced at the same time (Supplementary Table S2). Fragments of 200 to 300 bp specific to these homologous genes in $N$. benthamiana were used to construct tobacco rattle virus (TRV)2 VIGS vectors (primers are shown in Supplementary Table S1). Real-time quantitative reverse-transcription PCR (qRT-PCR) was used to measure the silencing efficiency of these constructs (primers are shown in Supplementary Table S2). Transcript levels of these genes were reduced at least $30 \%$ compared with the levels in control plants (Fig. 4).

Compared with control plants, silencing of the MEE32, $M G P 1$, and $P P R$ genes induced phenotypic changes. Genesilenced plants showed yellowing, lethality, and rolled leaves, respectively (Supplementary Fig. S2). The NbMGP1-silenced plants could not survive normally but the NbPPR- and NbMEE32-silenced plants could be efficiently infected by
$R$. solanacearum and showed wilting symptoms comparable with the control TRV:00. In all, 24 tobacco plants were silenced for each gene used for silencing. Subsequently, we performed soildrenching inoculation of gene-silenced plants with the $R$. solanacearum K60 strain, and the survival of the tobacco plants was monitored, except for the $N b M G P 1$-silenced plants that showed the lethal phenotype (Fig. 5A). Strain UW551 is classified as phylotype IIB, and these phylotype strains have strong pathogenicity to potato but not to tobacco, whereas the strain K60 is classified as phylotype IIA, and these phylotype strains have strong pathogenicity to tobacco. We found that the susceptibility of the silenced lines to $R$. solanacearum changed to varying degrees. Compared with that in the control plants, tobacco plants with silenced PPR, MEE32, LRX1, HSP22, and EIF4G genes showed no change in susceptibility, whereas those with silenced miraculin, HBP2, and TOM20 genes showed more severe symptoms and a reduced survival rate, and PP1-silenced lines exhibited increased resistance in response to $R$. solanacearum (Fig. 5B). The results of three repeated experiments are shown in Figure 5 and Supplementary Figures S3 and S4.

\section{Transcriptional expression of the identified proteins in potato roots.}

To examine whether the observed up- and downregulation of protein abundance was due to changes at transcriptional level, we measured the mRNA levels of the 21 genes corresponding to the DAP identified (Fig. 6). A part of the root samples prepared for proteomic analysis was used for total RNA isolation, to ensure the reliability of the proteins and transcripts. Total RNA together with primers designed for the genes were used for qRT-PCR analysis (Supplementary Table S3). The transcriptional levels of HSP 22, HBP2, TOM20, PP1, oxidoreductase, and ZKT did not

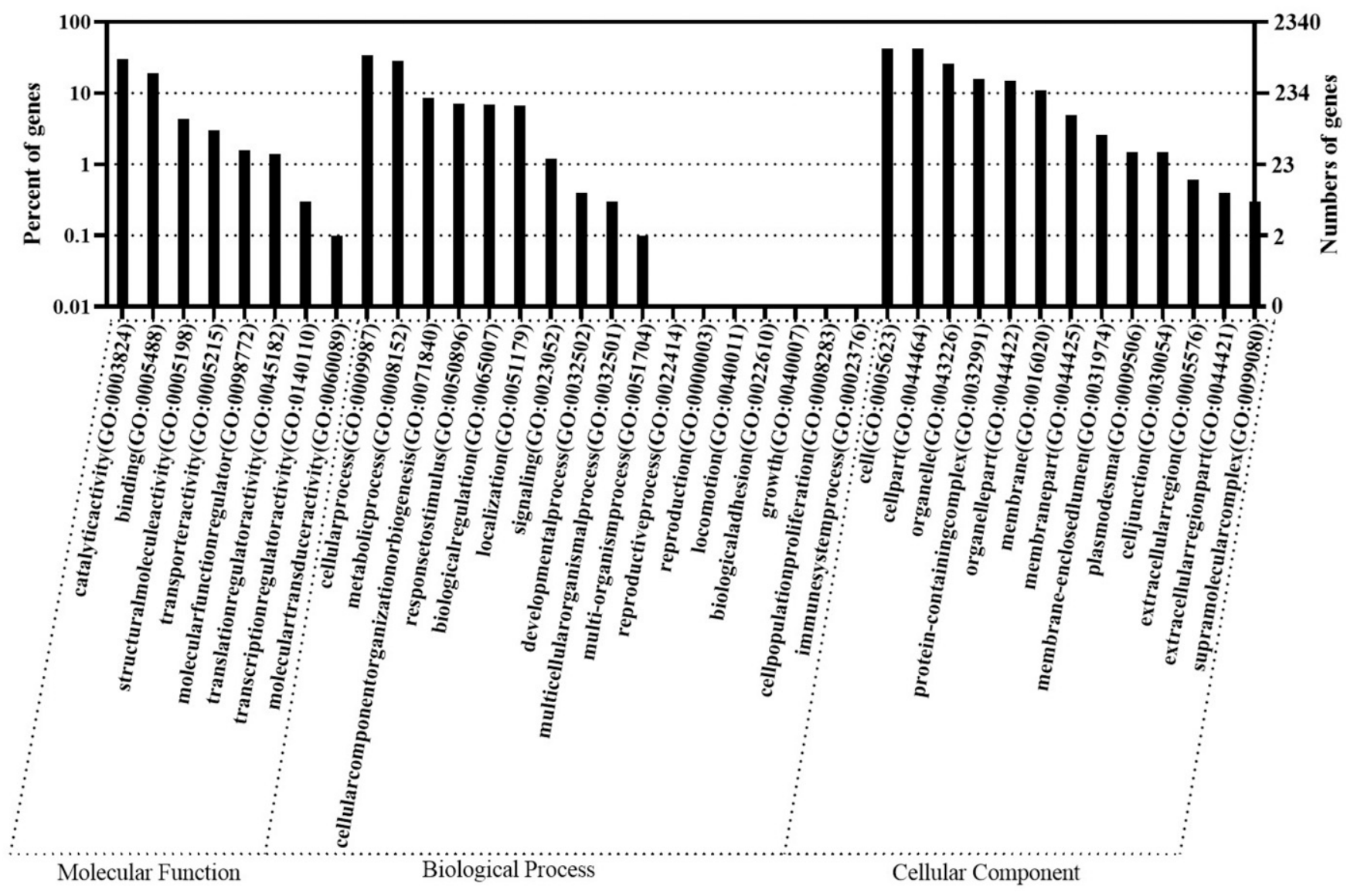

Fig. 2. Gene ontology (GO) analysis by PANTHER for all iTRAQ proteins. In addition to each category, the percentage of gene frequency was reported. The number of assigned genes may be greater than the number of recognized genes because the same gene can be included in different categories. 
change significantly in potato roots following inoculation with the $R$. solanacearum WT and $h r c \mathrm{~V}$ mutant strains, wherein the HSP22, HBP2, TOM20, and PP1 were posttranscriptionally downregulated upon $R$. solanacearum infection.

\section{Presence of T3Es decreased abundance without significantly affecting the transcriptional level in four downregulated proteins.}

Bacteria cannot inject effectors into host cells to perform their functions when the T3SS is inactivated, suggesting that DAPs are likely the result of the influence of T3Es. The downregulation of four proteins with no change at the transcriptional level can be attributed to the existence of T3Es.

To examine whether the downregulation of HBP2, PP1, HSP22, and TOM20 proteins was due to T3Es, we transiently coexpressed the downregulated proteins and T3Es in $N$. benthamiana. In a previous study, 33 core effector proteins were identified by analyzing the effector repertoire of 13 sequenced phylotype IIB strains (Table 3) (Zheng et al. 2019). In all, 33 FLAG-tagged T3Es and four HA-tagged expression vectors corresponding to the downregulated proteins were constructed for this work. Tobacco leaves were infiltrated with coexpressing FLAG-tagged effectors and HA-tagged downregulated proteins. Coexpression of FLAG-tagged green fluorescent protein and HA-tagged downregulated proteins were infiltrated as a negative control on the other side of tobacco leaves (Supplementary Fig. S5). Analysis of the abundance of these four proteins (Supplementary Fig. S6) in the two samples showed that, when these four proteins were coexpressed with T3Es, the protein abundance decreased significantly (Fig. 7). The protein abundance of TOM20 was decreased significantly when it was coexpressed with RipAE, RipBH, RipC1, RipE1, and RipG7 effectors. A significant decrease in the protein abundance of HSP22 was observed following coexpression with the RipAC, RipAD, RipAE, RipAP, RipAR, RipAT,
RipAV, RipB, RipC1, RipE1, RipF2, RipG2, RipG6, RipG7, RipH1, RipN, RipTPS, and RipV1 effectors. Similarly, the abundance of the HBP2 protein showed a significant decrease when it was coexpressed with the RipAD, RipAP, RipAV, RipB, RipBH, RipE1, RipG6, RipG7, and RipH1 effectors, and the abundance of the PP1 protein showed a significant decrease when it was coexpressed with the RipAC, RipAE, RipAM, RipAP, RipAJ, RipAR, RipAT, RipB, RipE1, RipG2, RipG6, and RipH1 effectors. The results of the effector and potato protein coexpression were summarized into a network (Fig. 8). The network shows effectors that decrease potato proteins abundance connected to potato protein by lines of the same color.

\section{DISCUSSION}

In vitro pathosystems have become a very effective technique to study the early infection of vascular pathogen $R$. solanacearum (Lu et al. 2018; Vasse et al. 2000; Zolobowska and Van Gijsegem 2006). In our study, we have used in vitro-grown potato for GUS staining, colony count, and protein sample preparation. T3Es represent the key weapon used by $R$. solanacearum to counteract host immunity (Van Gijsegem et al. 1993; Zheng et al. 2019). The T3SS knockout mutant cannot deliver T3Es into plant cells, resulting in the loss of pathogenicity (Etchebar et al. 1998; Frey et al. 1994). Microbial localization and visualization can help determine the interactions between pathogens and their host plants (Ferreira et al. 2017). GUS staining is one means of detecting the localization of strains in plants. To identify the localization and colonization differences between a WT $R$. solanacearum strain and T3SS mutant strains inoculated in potato plants, we detected the localization of both strains by GUS staining and tracked the bacterial populations in the plant roots. The UW551::GUS strains were readily detected in potato plants by their lethal effects and spreading over the entire plant soon after

Table 1. Root proteins with significant differential abundance following inoculation of potato with wild-type (WT) Ralstonia solanacearum or its type III secretion system mutant strain, identified by their best hit protein or gene

\begin{tabular}{|c|c|c|c|c|}
\hline Solanum tuberosum $^{\text {a }}$ & Best matching gene product ${ }^{b}$ & MW (kDa) & FC $(\mathrm{WT} \text { or } h r c \mathrm{~V})^{\mathrm{c}}$ & $P$ value $^{c}$ \\
\hline M1AGQ5 & Heat shock protein 60 (HSP60) & 60.3 & 4.418604651 & $7.21 \mathrm{E}-05$ \\
\hline M1CSI8 & Heat shock protein (HSP70) & 70.8 & 1.836534358 & 0.000183745 \\
\hline M1B7H0 & $\begin{array}{l}\text { FKBP type peptidyl-prolyl cis-trans } \\
\text { isomerase (FKBP16-3) }\end{array}$ & 25.5 & 1.807782466 & 0.006929319 \\
\hline M0ZYM1 & Midasin-like (MDN1) & 43.9 & 1.748399247 & $6.80 \mathrm{E}-05$ \\
\hline M0ZKQ8 & Chloroplastic lipocalin (CHL) & 30.4 & 1.565553746 & 0.013781156 \\
\hline M1AZP7 & Threonine dehydratase biosynthetic (OMR1) & 64.7 & 1.501545595 & $8.82 \mathrm{E}-06$ \\
\hline M1D527 & Protein binding protein (ZKT) & 36.4 & 1.476069462 & 0.022483707 \\
\hline M1AZT7 & Germin-like protein (GER3(a)) & 22 & 1.470679012 & 0.000730884 \\
\hline M1B3M1 & Germin-like protein (GER3(b)) & 21.5 & 1.445501097 & 0.00668519 \\
\hline M1BF20 & Oxidoreductase & 39.4 & 1.431206764 & 0.002113528 \\
\hline M1AJD8 & Low psii accumulation 3 (LPA3) & 27.7 & 1.426017497 & 0.028994609 \\
\hline M1A0Z7 & $\begin{array}{l}\text { Mitochondrial small heat shock protein } \\
\text { (HSP22) }\end{array}$ & 23.9 & 0.705955956 & 0.000634315 \\
\hline M1CER0 & $\begin{array}{l}\text { Dehydroquinate dehydratase/shikimate } \\
\text { dehydrogenase (MEE32) }\end{array}$ & 24 & 0.705530217 & 0.003383769 \\
\hline M1CKA5 & Miraculin & 22.1 & 0.701395573 & 0.000247865 \\
\hline M1A616 & Leucine-rich repeat/extension (LRX1) & 79.1 & 0.689750693 & 0.000275945 \\
\hline M1BT09 & $\begin{array}{l}\text { Mitochondrial import receptor subunit } \\
\text { TOM20 (TOM20) }\end{array}$ & 22.7 & 0.67679558 & 0.005436501 \\
\hline M1BTL1 & $\begin{array}{l}\text { Pentatricopeptide repeat-containing protein } \\
\text { (PPR) }\end{array}$ & 82.6 & 0.673297003 & 0.000749548 \\
\hline M1ARE5 & Soul heme-binding family protein (HBP2) & 22.2 & 0.647744946 & $5.47 \mathrm{E}-07$ \\
\hline M0ZN99 & $\begin{array}{l}\text { Eukaryotic translation initiation factor } 4 \mathrm{G} \\
(\text { EIF4G) }\end{array}$ & 195.8 & 0.577300931 & 0.000792221 \\
\hline P80496 & ATP synthase 24 kDa subunit (MGP1) & 27.7 & 0.572877736 & 0.001338535 \\
\hline M1C5B7 & Serine/threonine-protein phosphatase (PP1) & 47 & 0.487826472 & $9.40 \mathrm{E}-05$ \\
\hline
\end{tabular}

a Accession numbers were acquired from the liquid chromatography tandem mass spectrometry data.

b Best matches were based on accession number searches against the Solanaceae Genomics Resource and NCBI protein databanks.

c Differentially accumulated proteins were considered as those displaying a fold change (FC) $>1.40$ or $<0.71$ in relative abundance and a $P$ value $<0.05$. 
inoculation. In contrast, the GUS signal of the T3SS mutant strain was detected only in the roots and with a low population density. The results confirmed that the pathogenicity of $R$. solanacearum was related to the T3SS and the injection of T3E effector proteins into plant cells and that the T3Es play a key role in pathogen infection. Due to the lack of T3SS, effectors cannot inhibit plant immune response, resulting in restrictions on the proliferation and pathogenicity of pathogens. We infer that effectors may act on certain proteins in the root to help pathogens infect plants.

Based on the results of the bacterial quantification in the roots, we infer that the pathogen-plant interaction peaks at 6 days postinoculation. Proteomic analysis was performed based on the difference in bacterial density between the WT and the T3SS mutant strains infecting potato roots, leading to the identification of 21 DAPs. Given that the mechanisms involved in the upregulation of protein expression may be complex, we concentrated on determining whether the downregulated proteins were related to plant resistance in tobacco by VIGS. Because there is no mature VIGS system applying in potato to quickly test those DAPs functions thus far, we silenced homologous genes in the model plant $N$. benthamiana. With this system, we could only test the function of the homolog genes in $N$. benthamiana. The silencing of TOM20, PP1, HBP2, and miraculin in tobacco plants significantly changed the resistance of plants to $R$. solanacearum. TOM20 is a marker of oxidative phosphorylation, and increased oxidative phosphorylation can lead to increased ROS production (Urvalek et al. 2015). ROS are considered a representative cellular immune response triggered by PAMP (Sang and Macho 2017) and an important line of defense against pathogen invasion (Aver'yanov et al. 2001). In tomato, increased ROS generation can improve resistance to bacterial wilt (Mandal et al. 2011), and the evidence suggests that $R$. solanacearum infection can induce ROS production in tolerant plants (Ferreira et al. 2017). The results of our study suggest that $R$. solanacearum can inhibit ROS production in the process of infection because the TOM20 protein was downregulated in plants inoculated with the WT strain compared with that in plants inoculated with the T3SS mutant strain, and TOM20 silencing increased plant susceptibility to infection. HBP2 is a heme-binding protein, and the homologous Arabidopsis gene AtHBP5 is reported to be involved in the antioxidant pathway. Overexpression of AtHBP5 in plants can reduce $\mathrm{H}_{2} \mathrm{O}_{2}$ content (Lee et al. 2012). ROS production in plants increases significantly in the early resistance response against pathogens (Mehdy 1994); however, excessive ROS production can cause damage to plants, including enzyme inactivation and cell death (Grene 2002). HBP2-silenced plants cannot defend against ROS damage, which further aggravates plant damage. The Miraculin protein has a Kunitz inhibitor domain and can act as a moderate trypsin protease inhibitor (Ohkura et al. 2018). Plant Kunitz-type inhibitors are considered to play an important role in defending against pathogen invasion (Bendre et al. 2019), and Kunitz proteinases are reported to be activated by jasmonate (Yamchi et al. 2018). The silencing of Miraculin indicated that the gene is associated with plant resistance, which merits further investigation. The PP1 protein is a protein phosphatase and plays an important role in plant immune regulation (Liu et al. 2020) and is reported to be a negative regulator of plant defenses, consistent with the results of this study. We will investigate this discrepancy in future work using potato transgenics. In this study, four of the downregulated genes were related to plant resistance to pathogen attack, which shows the reliability of our experimental design.

\section{Cellular component}

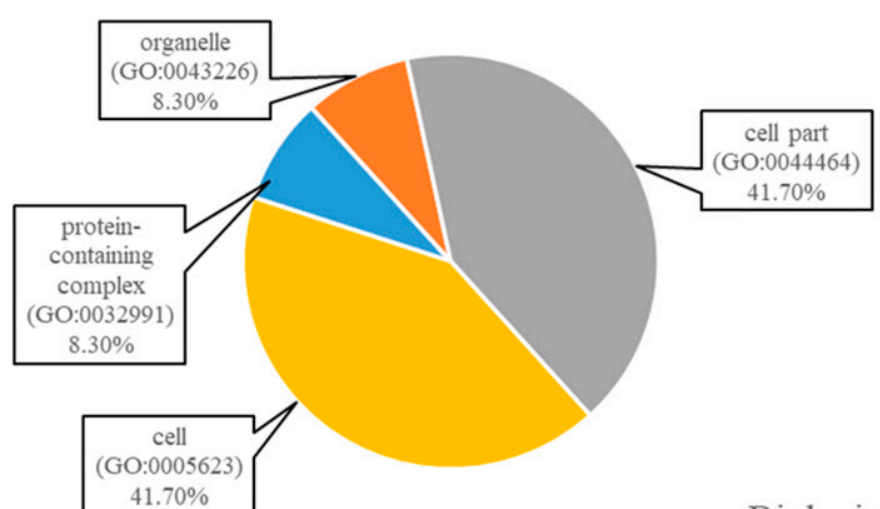

\section{Molecular function}

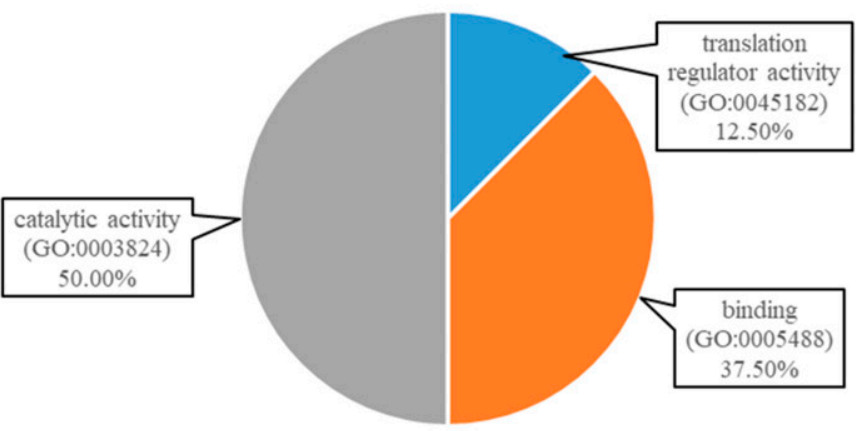

\section{Biological process}

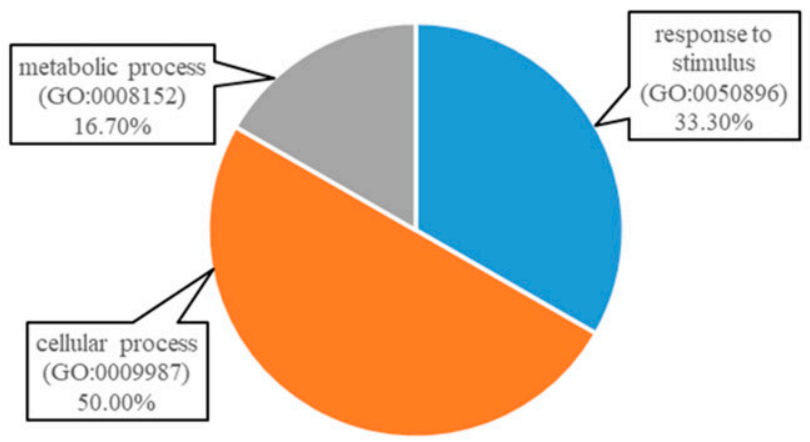

Fig. 3. Gene ontology (GO) annotation pie chart of 21 differentially expressed genes via PANTHER classification analysis. GO hits for these genes were assigned to molecular functions, cellular components, and biological process. In all, 6 genes were annotated in biological processes, 8 genes in molecular functions, and 12 genes in cellular components categories. The percentage of function hits is indicated in parentheses. 
The expression of DAPs at the transcription level shows no difference after inoculation with the $R$. solanacearum WT and hrcV mutant strains (Fig. 6), which is consistent with the transcriptome data of wild potato $S$. commersonii in potato roots upon $R$. solanacearum infection (Zuluaga et al. 2015). We found that 4 of the 10 downregulated proteins showed unaltered transcriptional expression, suggesting that changes in the abundance of these proteins are likely to occur at the protein level. In plants inoculated with T3SS mutant strains, effector proteins cannot enter into plant cells (Coll and Valls 2013). We believe that the downregulation of the four proteins was caused by the T3Es; therefore, we aimed to identify effectors that influence each one of potato proteins. To verify this, we employed the $N$. benthamiana transient expression system, an efficient and high-level model system for transient protein expression (Xu et al. 2015), to directly coexpress the selected proteins with the effectors. The results indicated that the downregulation of these four proteins was likely to have resulted from the combined action of multiple effector proteins. Interestingly, the abundance of HSP22 was decreased by 18 effectors when coexpressed in tobacco; however, the result of VIGS showed that it did not have an effect on potato immunity. This circumstance may be due to VIGS experimental systems. The VIGS systems have some limitations in potato gene function verification. In our cases, HSP22 could be downregulated by 18 effectors, which is unusual. Two reasons may explain this: one is the limitation of the VIGS system and the other is the redundancy of T3Es. Due to the redundancy of T3Es, multiple effectors may play some role in the perturbation of plant immunity.

Identifying the toxicity associated with a single effector has been reported to be difficult owing to functional redundancy (Poueymiro et al. 2014), and our results also confirmed this. Studies have shown that the effectors of $R$. solanacearum can inhibit plant defense mechanisms, regulate host metabolism, or avoid bacterial recognition through a variety of molecular mechanisms. It has been shown that $R$. solanacearum effectors can suppress plant defense mechanisms, modulate the host metabolism, or avoid bacterial recognition through a wide variety of molecular mechanisms (Landry et al. 2020). Although the inhibitory effect of T3Es on PTI has been widely reported, there are still few reports on the $\mathrm{T} 3 \mathrm{E}$ and its biochemical properties in inhibiting ETI (Yu et al. 2020). After the T3SS was knocked out, the pathogen could not inject the effectors to plant cells and lost the ability to suppress regulated plant immunity. Therefore, the decreases of DAPs were likely to be caused by the presence of T3Es, and we believe that the screened genes may be directly or indirectly involved in plant immune regulation.

This study aimed to screen effector-related plant proteins by proteomics. In our study, we showed that T3Es play a key role in potato colonization and multiplication. In particular, there were four genes that affect plant resistance mentioned in the VIGS experiment and four other genes that are inhibited by

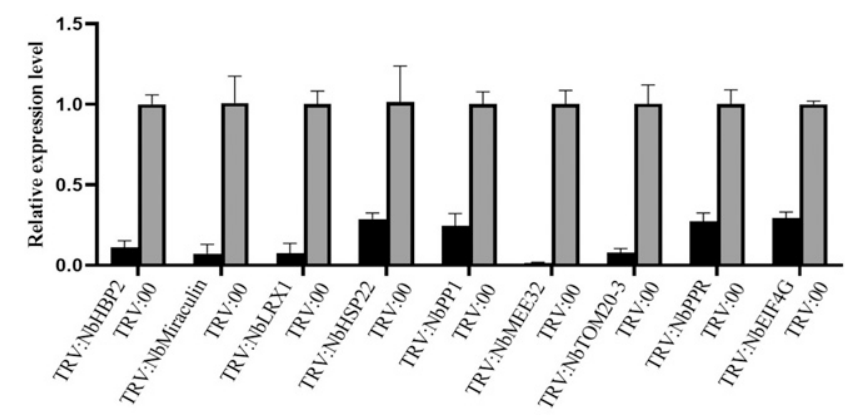

Fig. 4. Relative gene expression in the gene-silenced plants. Targeted genes exhibit a 70 to $99 \%$ reduction in expression in silenced plants compared with that of mock-treated TRV:00 plants, which were set to ' 1 '. Experiments were repeated three times, with three independent biological repetitions each time. Error bars indicate the standard error. Relative transcript levels of analyzed tobacco genes were normalized to the transcript levels of NbActin.

Table 2. Nicotiana benthamiana homologs of the 10 genes downregulated in potato roots inoculated with wild-type Ralstonia solanacearum UW551, and its relative gene expression

\begin{tabular}{lccc}
\hline Gene name & Solanum tuberosum (accession number) & N. benthamiana sequence ID & Relative gene expression $^{\mathbf{b}}$ \\
\hline EIF4G & M0ZN99 & Niben101Scf10210g01004.1 & 0.029 \\
& $\ldots$ & Niben101Scf06902g02007.1 & 0.046 \\
MEE32 & M1CER0 & Niben101Scf04146g01023.1 & 0.049 \\
& $\ldots$ & Niben101Scf02709g04001.1 & 0.030 \\
TOM20 & $\ldots$ & Niben101Scf04216g05005.1 & 0.172 \\
& M1BT09 & Niben101Scf00109g10030.1 & 0.001 \\
& $\ldots$ & Niben101Scf03766g01008.1 & 0.036 \\
PPR & $\ldots$ & Niben101Scf05095g01004.1 & 0.057 \\
& $\ldots$ & Niben101Scf14939g01027.1 & 0.028 \\
MGP1 & M1BTL1 & Niben101Scf05649g05013.1 & 0.011 \\
& $\ldots$ & Niben101Scf00751g04001.1 & 0.344 \\
PP1 & P80496 & Niben101Scf05057g02005.1 & 0.118 \\
& $\ldots$ & Niben101Scf08308g04016.1 & 0.240 \\
HSP22 & $\ldots$ & Niben101Scf01942g05024.1 & 0.021 \\
& M1C5B7 & Niben101Scf02724g05005.1 & 0.004 \\
LRX1 & $\ldots$ & Niben101Scf11953g03005.1 & 0.026 \\
HBP2 & $\ldots$ & Niben101Scf03064g08007.1 & 0.028 \\
Miraculin & $\ldots$ & Niben101Scf00317g09001.1 & 0.007 \\
& M1A0Z7 & Niben101Scf04091g00013.1 & 0.042 \\
\hline
\end{tabular}

\footnotetext{
a These genes were searched against the Solanaceae Genomics Network.

${ }^{b}$ Relative expression of target genes is expressed in comparison with a reference gene (NbActin).
} 
multiple effectors at the protein level in the coexpression experiment, and, interestingly, three of the four genes ( $P P 1$, $T O M 20$, and HBP2) in the results of the two experiments are the same. These three genes have the value of further research on their relationship with plant immunity.

\section{MATERIALS AND METHODS}

Plant materials.

Potato plants (S. chacoense accession C9701) were grown at 18 to $25^{\circ} \mathrm{C}$ in a glasshouse with cycles of $16 \mathrm{~h}$ of light and $8 \mathrm{~h}$ of

A
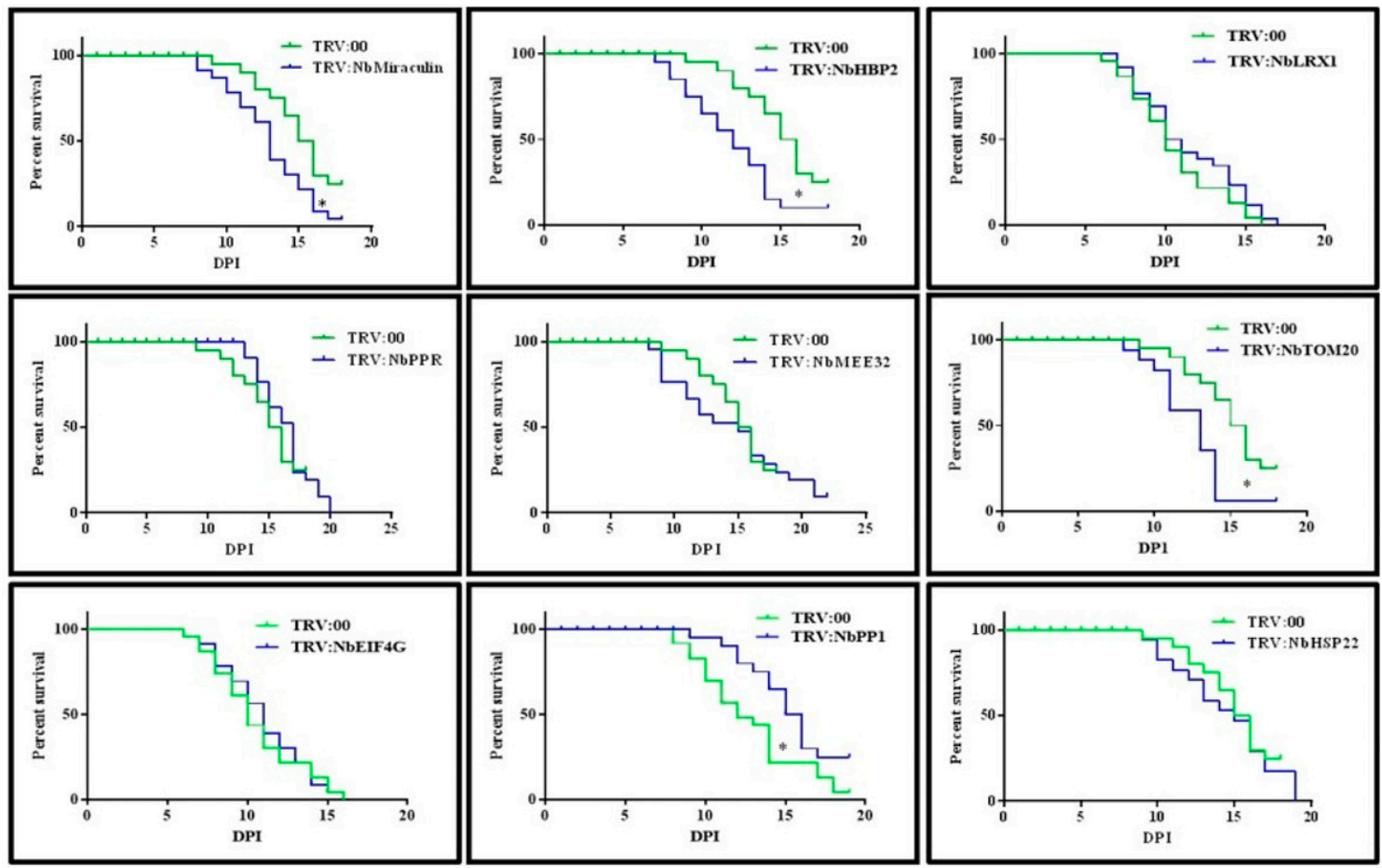

B
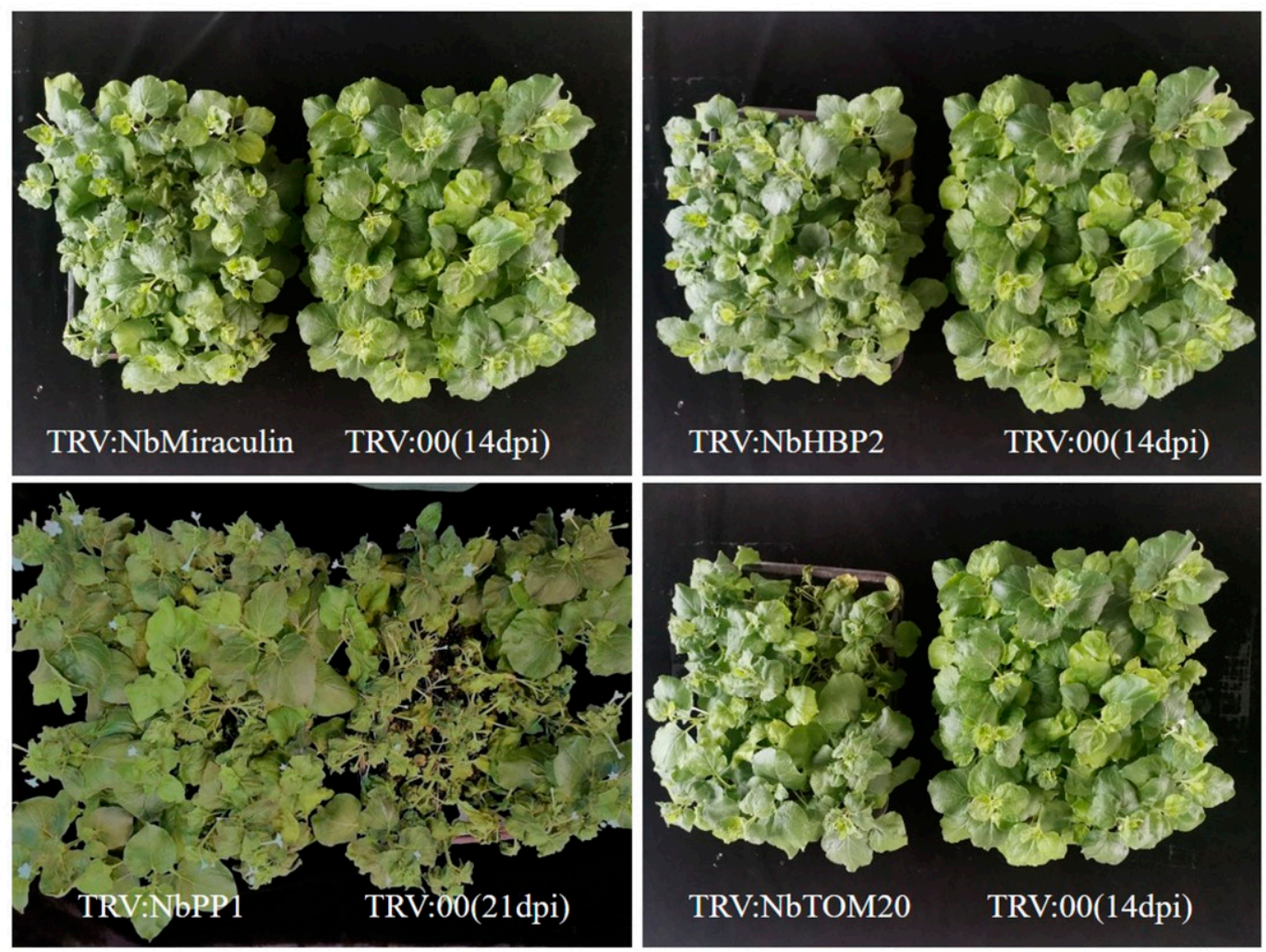

Fig. 5. Virus-induced gene silencing of target genes changed the susceptibility of tobacco to Ralstonia solanacearum strain K60. A, Survival analysis of genesilenced plants (named as TRV:target gene) inoculated with $R$. solanacearum strain K60. Statistical analysis was performed via the log-rank test and the GehanBreslow-Wilcoxon test (* indicates $P<0.05$ ). Each point represents the survival rates of one independent experiment, comprising 24 silenced plants per treatment. B, Disease symptoms of the empty vector control plants inoculated with $R$. solanacearum K60 by root irrigation at 14 or 21 days postinoculation (dpi). 
darkness. After 3 weeks, plants were sown in plastic boxes with soil mix (Tref Substrates BV, Moerdijk, The Netherlands) and used as the susceptible WT species for virulence identification.

Four C9701 potato plants were micropropagated in a sterile culture box from a node with $30 \mathrm{ml}$ of Murashige and Skoog medium with sucrose at $30 \mathrm{~g} / \mathrm{liter}$ and kept at $22^{\circ} \mathrm{C}$ with cycles of $16 \mathrm{~h}$ of light and $8 \mathrm{~h}$ of darkness. After 2 weeks, plants were used for the GUS assay.

$N$. benthamiana plants were grown in a soil mix in plastic pots under long-day (16 h of light) conditions at $22^{\circ} \mathrm{C}$ and relative humidity of $70 \%$ in a glasshouse.

\section{Bacterial materials.}

Strain UW551 is classified as phylotype IIB, and it has a strong pathogenicity to potato but not to tobacco. Strain K60 is classified as phylotype IIA, and it has a strong pathogenicity to tobacco. $R$. solanacearum strains was grown on $\mathrm{BG}$ agar (bactopeptone at $10 \mathrm{~g} / \mathrm{liter}$, casamino acids at $1 \mathrm{~g} / \mathrm{liter}$, and glucose at $2.5 \mathrm{~g} /$ liter) plated at $28^{\circ} \mathrm{C}$ for $48 \mathrm{~h}$.

Construction of $\mathrm{R}$. solanacearum hrcV mutant and GUSproducing strains. To generate the $R$. solanacearum T3SS mutant strain, the whole $h r c \mathrm{~V}$ gene was replaced with $\mathrm{Km}^{r}$. Each sequence contains the target gene, and its flanking region (500 to $1,000 \mathrm{bp}$ ) was amplified from the genome of strain UW551 and inserted into a pEASY-blunt vector. Reverse amplification of the target gene was used to delete the target gene that produces only linear vectors with flanking regions. Using the ClonExpress II onestep cloning kit (Vazyme Biotech), the $\mathrm{Km}^{r}$ cassette that contained the promoter and terminator was inserted into the linear vector to create the pEASY-flanking region- $\mathrm{Km}^{r}$ vector. The $\mathrm{Km}^{\mathrm{r}}$ cassette fragment harboring the flanking regions of the mutant gene was then amplified and purified for the transformation of the $R$. solanacearum strain (Jacobs et al. 2013).

The GUS-producing strains were constructed via homologous recombination, and the gene GUS with a psbA promoter and a $\mathrm{Km}^{\mathrm{r}}$ cassette were inserted into a permissive chromosomal site between RRSL_04294 and RRSL_04295, just like the construction of the mutant.

\section{GUS assay.}

A whole plant inoculated with GUS-producing strains was vacuum infiltrated with a GUS staining solution $(1 \mathrm{mM}$ sodium phosphate buffer [pH 7] $10 \mathrm{mM}$ EDTA, $0.1 \%$ Triton-X, chloramphenicol at $100 \mu \mathrm{g} / \mathrm{ml}, 2 \mathrm{mM}$ potassium ferrocyanide, $2 \mathrm{mM}$ potassium ferricyanide, and X-glucuronide at $0.5 \mathrm{mg} / \mathrm{ml}$ ) for $15 \mathrm{~min}$, incubated overnight at $37^{\circ} \mathrm{C}$, then destained using $70 \%$ ethanol (Pecinka et al. 2009). Selected plants were observed from day 0 to 7 after inoculation for infection by GUSproducing strains of $R$. solanacearum.

\section{VIGS assay.}

The TRV-based VIGS vector is the most efficient VIGS vector thus far (Dong et al. 2007). To construct 10 vectors for VIGS, parts of the 3-untranslated region of the 10 target genes were cloned into the destination vector pTRV2. All of the primers used in VIGS vector construction are listed in Supplementary Table S1. For the VIGS assay, TRV vectors were transformed into Agrobacterium tumefaciens strain GV3101 by electroporation (Holsters et al. 1980). Bacteria containing TRV1 or TRV2 plasmids were incubated overnight at $28^{\circ} \mathrm{C}$ with shaking and then resuspended in infiltration buffer (10 mM morpholineethanesulfonic acid, $10 \mathrm{mM}$ $\mathrm{MgCl} 2,200 \mu \mathrm{M}$ acetosyringone, $\mathrm{pH}$ 5.6). Agrobacterium cultures at an optical density at $600 \mathrm{~nm}\left(\mathrm{OD}_{600}\right)=0.5$ containing TRV1 or TRV2 derivative plasmids were mixed in a 1:1 ratio. After $3 \mathrm{~h}$ of incubation, the mixed Agrobacterium cultures were injected into the leaves of four-leaf-stage $N$. benthamiana plants. A gene- silenced phenotype appeared in the new leaves 2 weeks postinjection (Wang et al. 2013).

\section{qRT-PCR.}

For gene expression analysis, total RNA was extracted using a Plant RNA kit (Bio-tek, Winooski, VT, U.S.A.) in accordance

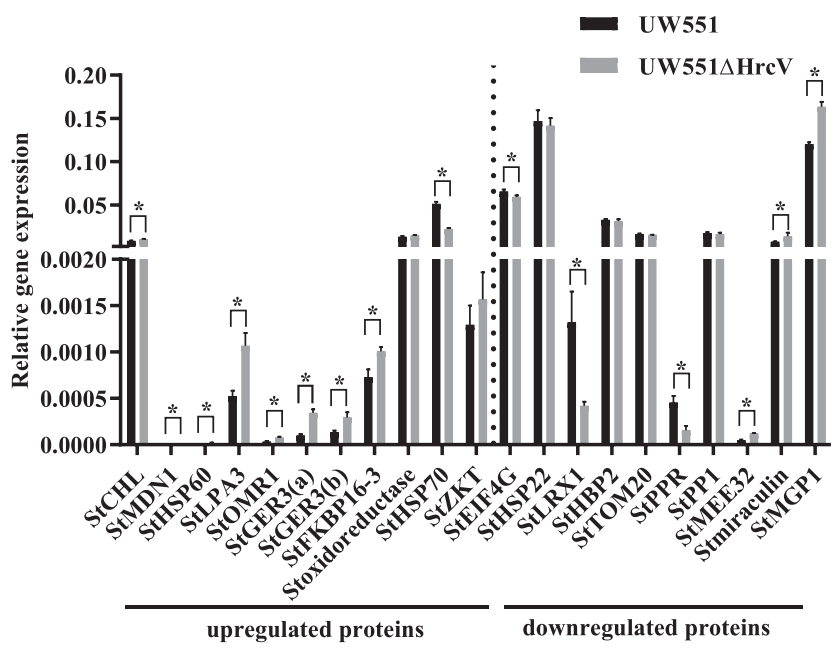

Fig. 6. Relative gene expression of the differentially accumulated proteins Data represent means \pm standard deviation, $n=3$; an asterisk $(*)$ indicates $P<0.05$, multiple $t$ tests, corrected for multiple comparisons using the Holm-Sidak method.

Table 3. Core type III effectors (T3Es) $(n=33)$ identified in Ralstonia solanacearum comparative analysis of 13 sequenced phylotype IIB strains ${ }^{\mathrm{a}}$

\begin{tabular}{|c|c|}
\hline Effector name & Description $^{b}$ \\
\hline RipA2 & AWR2 \\
\hline RipA5-2 & AWR5 \\
\hline RipAB & NLS harboring protein \\
\hline RipAC & LRR domain \\
\hline RipAD & $\ldots$ \\
\hline RipAE & Putative acetyltransferase \\
\hline RipAI & $\ldots$ \\
\hline RipAM & $\ldots$ \\
\hline RipAJ & $\ldots$ \\
\hline RipAN & $\ldots$ \\
\hline RipAP & $\ldots$ \\
\hline RipAR & Ubiquitin ligase domain \\
\hline RipAT & $\ldots$ \\
\hline RipAV & $\ldots$ \\
\hline RipAY & Glutamyl cyclotransferase \\
\hline RipB & Nucleoside Nribohydrolase \\
\hline RipBH & $\ldots$ \\
\hline RipC1 & HAD-like phosphatase \\
\hline RipD & $\ldots$ \\
\hline RipE1 & $\ldots$ \\
\hline RipE2 & $\ldots$ \\
\hline RipF1 & T3SS translocator \\
\hline RipF2 & T3SS translocator \\
\hline RipG2 & F-box LRR GALA2 \\
\hline RipG6 & F-box LRR GALA6 \\
\hline RipG7 & F-box LRR GALA7 \\
\hline RipH1 & HLK \\
\hline RipN & Nudix hydrolase \\
\hline RipO1 & $\ldots$ \\
\hline RipR & $\ldots$ \\
\hline RipTPS & Trehalose-phosphate synthase \\
\hline RipU & $\ldots$ \\
\hline RipV1 & Ubiquitin ligase domain \\
\hline
\end{tabular}

${ }^{a}$ Effector name and functional description were obtained from the T3E database (Peeters et al. 2013).

b $\mathrm{LRR}=$ leucine-rich repeat and T3SS = type III secretion system. 
with the manufacturer's instructions. First-strand cDNA was synthesized using an iScript cDNA synthesis kit (Bio-Rad, Hercules, CA, U.S.A.). qRT-PCR was performed using SYBR Green Super mix (Bio-Rad) and a CFX96 Real-Time system (Bio-Rad), and the qRT-PCR data were analyzed as described previously (Livak and Schmittgen 2001). Three independent biological replicates of each treatment were performed, and three technical replicates were performed for each biological replicate. Primer pairs were designed outside the region of cDNA targeted for selected genes following the manufacturer's guidelines (Supplementary Tables S2 and S3). In each case, PCR conditions were $95^{\circ} \mathrm{C}$ for $15 \mathrm{~min}$, followed by 40 cycles of

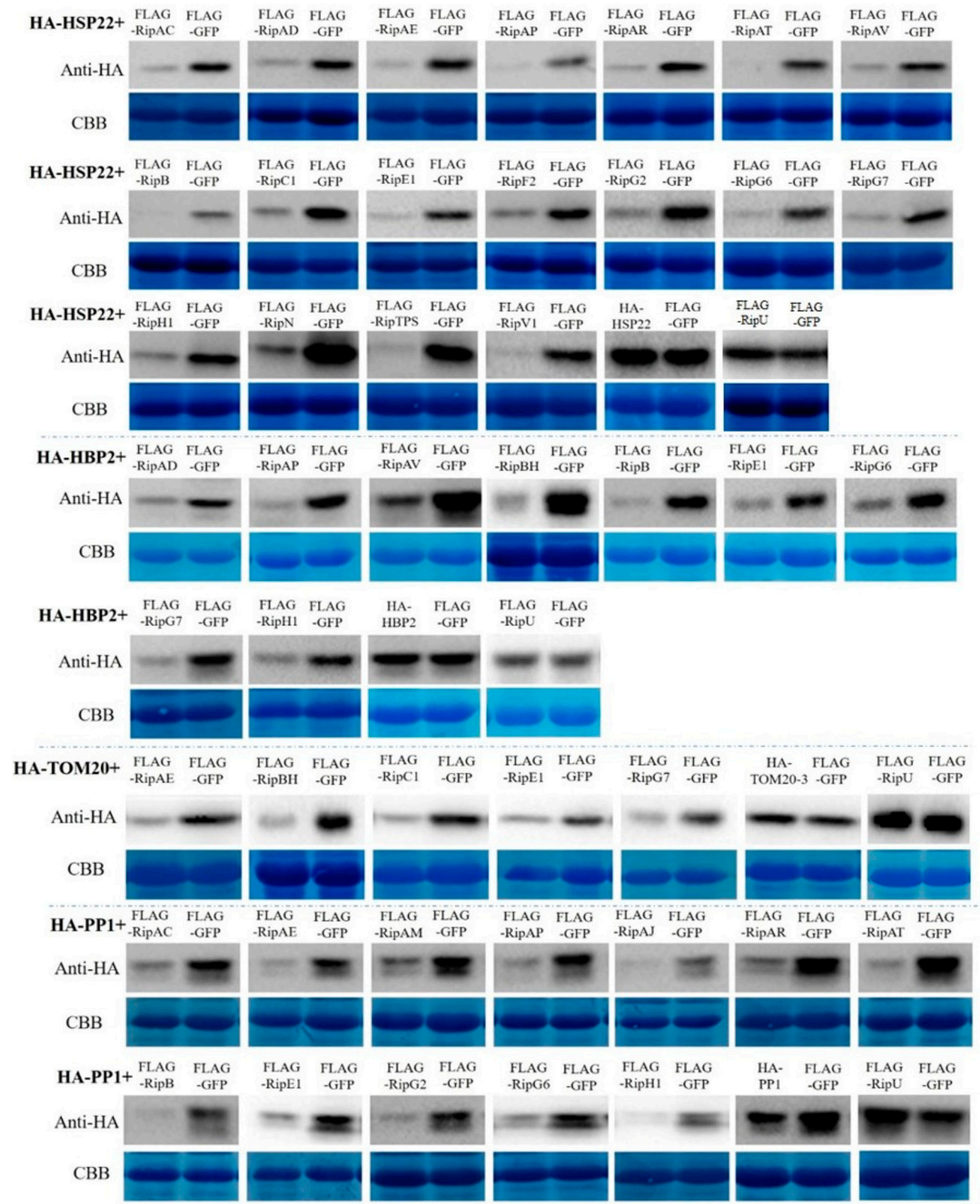

Fig. 7. Abundance of the potato proteins PP1, HSP22, HBP2, and TOM20 decreased when coexpressed with type III effectors. Detection of the abundance of HA-tagged potato protein PP1, HSP22, HBP2, and TOM20. An effector (RipU) was selected as a control that has no effect on the plant proteins. Proteins were extracted at $48 \mathrm{~h}$ postinfection (hpi). The experiment was conducted in triplicate. The protein loading is indicated by Coomassie Brilliant Blue (CBB) staining. $\mathrm{GFP}=$ green fluorescent protein. 
$95^{\circ} \mathrm{C}$ for $15 \mathrm{~s}, 60^{\circ} \mathrm{C}$ for $30 \mathrm{~s}$, and $72^{\circ} \mathrm{C}$ for $30 \mathrm{~s}$. Expressions in silenced plants were compared with that in the control TRV:00 plants. The potato gene Stefl $\alpha$ (XM_006343394) and tobacco gene Ntactin (XM_016658880) were used as internal reference genes (Nicot et al. 2005). All primers used in qRT-PCR are listed in Supplementary Tables S2 and S3.

\section{Pathogenicity assays.}

In vitro potato tests were used for GUS assays and bacterial quantification and inoculated with $5.0 \mathrm{ml}$ of $R$. solanacearum suspension $\left(\mathrm{OD}_{600}=0.1\right)$. Three independent tests, with eight potato plants per experiment, were carried out. Plant wilting symptoms were recorded every day and expressed according to a disease index scale $(0=$ no wilting; $1=25 \%, 2=50 \%$, and
$3=75 \%$ wilted leaves; and $4=$ death). To measure root colonization by $R$. solanacearum strains, from 0 to 9 days after inoculation, we sampled the middle of potato roots every day, and four inoculated plants per strain per time point were harvested in a sterile environment. The root segment was weighed, ground in $5 \mathrm{ml}$ of sterile water, and dilution plated onto BG medium; colonies were counted after $48 \mathrm{~h}$ of incubation at $28^{\circ} \mathrm{C}$. (Colburn-Clifford et al. 2010).

The soil drench is a method of pouring bacterial liquid directly into the soil and allowing pathogens to infect plants naturally, which was used for the VIGS lines and virulence assays. With respect to the infection of the VIGS lines, the surviving plants were recorded daily after inoculation. In total, $24(4 \times 6)$ silenced plants inoculated with $500 \mathrm{ml}$ of $R$. solanacearum suspension

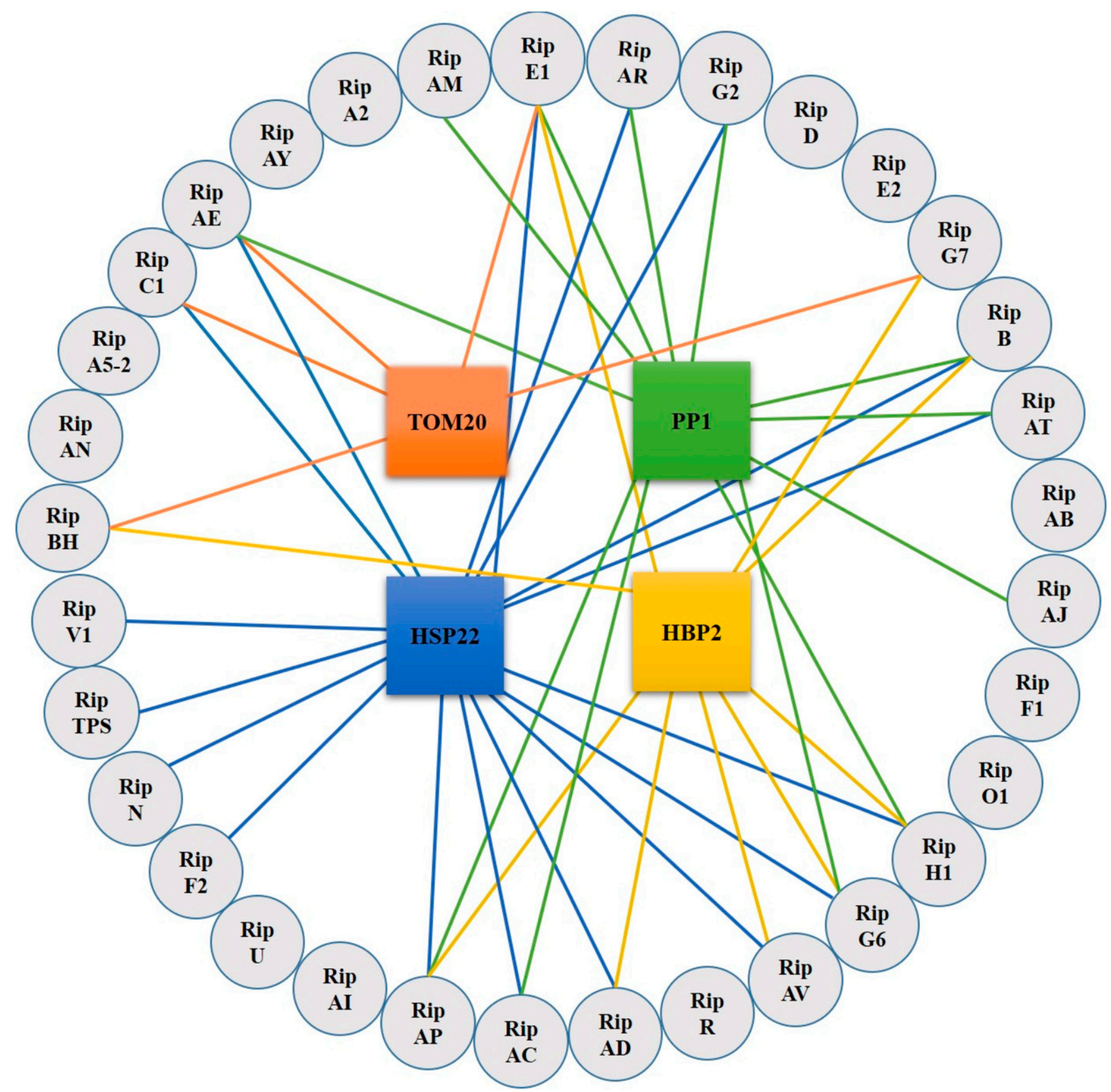

Fig. 8. A summary network of the effector/potato protein coexpression. Lines of the same color connect each of the four potato proteins (PP1 [green], HBP2 [yellow], HSP22 [blue], and TOM20 [orange]) to the effectors that led to their decreased abundance when coexpressed. 
$\left(\mathrm{OD}_{600}=0.1\right)$ were used for the analysis of the survival rates and three independent experiments were evaluated. The number of surviving plants was recorded daily after inoculation.

\section{Transient expression in $N$. benthamiana.}

Four- to six-week-old plants were used for transient expression assays. A. tumefaciens cultures (strain GV3101) carrying target constructs were cultured overnight in the presence of the appropriate antibiotics at $28^{\circ} \mathrm{C}$. Bacteria were pelleted, centrifuged, and resuspended in infiltration buffer, after which their concentration was adjusted to the required $\mathrm{OD}_{600}$ of 0.3 for immunoblots. After $3 \mathrm{~h}$ of incubation, the cultures were infiltrated into leaves of $N$. benthamiana plants.

\section{Immunoblot analysis.}

After $48 \mathrm{~h}$ of Agrobacterium-mediated transformation, tobacco leaves were ground in liquid nitrogen and extracted in extraction buffer $(100 \mathrm{mM}$ Tris $[\mathrm{pH}=8], 150 \mathrm{mM} \mathrm{NaCl}, 10 \%$ glycerol, $5 \mathrm{mM}$ EDTA, $2 \mathrm{mM}$ dithiothreitol [DTT], 1\% protease inhibitor cocktail, and $2 \mathrm{mM}$ phenylmethylsulfonyl fluoride). The homogenate was centrifuged at $15,000 \times g$ for 20 min. (Kadota et al. 2016). A 5x sodium dodecyl sulfate (SDS) loading buffer (250 mM Tris-HCL [pH 6.8], $10 \%$ [wt/vol] SDS, $0.5 \%$ [wt/vol] bromophenol blue, $50 \%$ [wt/vol] glycerol, and 5\% [wt/vol] $\beta$-mercaptoethanol) was added to the supernatant and heated at $95^{\circ} \mathrm{C}$ for $10 \mathrm{~min}$ on a heating block. Proteins were separated by $10 \%$ SDS-polyacrylamide gel electrophoresis, then transferred to polyvinylidene fluoride membranes (Bio-Rad), and the chemiluminescence bands were detected with ECL Plus reagent.

\section{Sample preparation and proteomic analyses.}

In this study, the root samples of 12 potato plants per treatment were harvested at 6 days postinoculation and partial root mixtures samples of 12 potato plants were sent for proteomic analyses. For each sample, $100 \mu \mathrm{g}$ of protein was mixed with $120 \mu \mathrm{l}$ of reducing buffer (10 mM DTT, $8 \mathrm{M}$ urea, and $100 \mathrm{mM}$ triethylammonium bicarbonate, $\mathrm{pH}$ 8.0) in an Amicon Ultra 0.5 Centrifugal Filter $(10 \mathrm{kDa})$ and was incubated at $60^{\circ} \mathrm{C}$ for $1 \mathrm{~h}$. Then, iodoacetamide was added to the solution with a final concentration of $50 \mathrm{mM}$ and incubated for $40 \mathrm{~min}$ at room temperature in the dark. The iTRAQ labeling proteomic and mass spectrometric data analyses were carried out by Shanghai LuMing Biological Technology Co., Ltd. (Elias and Gygi 2007; Wiśniewski et al. 2009). The raw mass spectrometry proteomics data have been deposited at iProX (Ma et al. 2019) with the data set identifier IPX0001659000.

\section{Bioinformatics.}

In this study, the biological and functional properties of all of the identified proteins were mapped with GO terms by PANTHER.

\section{ACKNOWLEDGMENTS}

We thank C. Allen and the late P. Prior for providing us with $R$. solanacearum strains; all members of the potato group in Huazhong Agricultural University for supporting this project; the Shanghai LuMing Biological Technology Co., Ltd. (Shanghai, China) for providing proteomics services; and Charlesworth for its linguistic assistance during the preparation of this manuscript.

\section{AUTHOR-RECOMMENDED INTERNET RESOURCES}

iProX: https://iprox.org

PANTHER: http://www.pantherdb.org/

Ralstonia solanacearum GMI1000, MOLK2 and IPO1609:

https:/iant.toulouse.inra.fr/bacteria/annotation/cgi/ralso.cgi
Solanaceae Genomics Network:

https://solgenomics.net/organism/nicotiana_benthamiana/genome

\section{LITERATURE CITED}

Aver'yanov, A. A., Pasechnik, T. D., Lapikova, V. P., and Gaivoronskaya, L. M. 2001. Fungitoxic responses of rice callus culture as an expression of inheritable resistance to blast. Implication of active oxygen. Plant Physiol. Biochem. 39:415-424.

Bendre, A. D., Suresh, C. G., Shanmugam, D., and Ramasamy, S. 2019. Structural insights into the unique inhibitory mechanism of Kunitz type trypsin inhibitor from Cicer arietinum L. J. Biomol. Struct. Dyn. 37: 2669-2677.

Bolwell, G. P. 1999. Role of active oxygen species and NO in plant defence responses. Curr. Opin. Plant Biol. 2:287-294.

Boucher, C. A., Barberis, P. A., and Demery, D. A. 1985. Transposon mutagenesis of Pseudomonas solanacearum: Isolation of Tn5-induced avirulent mutants. Microbiology 131:2449-2457.

Boucher, C. A., Van Gijsegem, F., Barberis, P. A., Arlat, M., and Zischek, C. 1987. Pseudomonas solanacearum genes controlling both pathogenicity on tomato and hypersensitivity on tobacco are clustered. J. Bacteriol. 169:5626-5632.

Brito, B., Aldon, D., Barberis, P., Boucher, C., and Genin, S. 2002. A signal transfer system through three compartments transduces the plant cell contact-dependent signal controlling Ralstonia solanacearum hrp genes. Mol. Plant-Microbe Interact. 15:109-119.

Brown, D. G., and Allen, C. 2004. Ralstonia solanacearum genes induced during growth in tomato: An inside view of bacterial wilt. Mol. Microbiol. 53:1641-1660.

Büttner, D. 2016. Behind the lines-actions of bacterial type III effector proteins in plant cells. FEMS Microbiol. Rev. 40:894-937.

Caldwell, D., Kim, B. S., and Iyer-Pascuzzi, A. S. 2017. Ralstonia solanacearum differentially colonizes roots of resistant and susceptible tomato plants. Phytopathology 107:528-536.

Cao, B., Liu, J., Qin, G., and Tian, S. 2012. Oxidative stress acts on special membrane proteins to reduce the viability of Pseudomonas syringae pv. tomato. J. Proteome Res. 11:4927-4938.

Champoiseau, P. G., Jones, J. B., and Allen, C. 2009. Ralstonia solanacearum race 3 biovar 2 causes tropical losses and temperate anxieties. Plant Health Prog. 10. https://apsjournals.apsnet.org/ doi/10.1094/PHP-2009-0313-01-RV

Chen, L., Guo, X., Xie, C., He, L., Cai, X., Tian, L., Song, B., and Liu, J. 2013. Nuclear and cytoplasmic genome components of Solanum tuberosum $+S$. chacoense somatic hybrids and three SSR alleles related to bacterial wilt resistance. Theor. Appl. Genet. 126:1861-1872.

Chiang, Y., and Coaker, G. 2015. Effector triggered immunity: NLR immune perception and downstream defense responses. Arabidopsis Book 2015:e0183.

Chisholm, S. T., Coaker, G., Day, B., and Staskawicz, B. J. 2006. Hostmicrobe interactions: Shaping the evolution of the plant immune response. Cell 124:803-814.

Colburn-Clifford, J. M., Scherf, J. M., and Allen, C. 2010. Ralstonia solanacearum Dps contributes to oxidative stress tolerance and to colonization of and virulence on tomato plants. Appl. Environ. Microbiol. 76:7392-7399.

Coll, N. S., and Valls, M. 2013. Current knowledge on the Ralstonia solanacearum type III secretion system. Microb. Biotechnol. 6:614-620.

Cui, H., Tsuda, K., and Parker, J. E. 2015. Effector-triggered immunity: From pathogen perception to robust defense. Annu. Rev. Plant Biol. 66: 487-511.

Darvill, A. G., and Albersheim, P. 1984. Phytoalexins and their elicitors-A defense against microbial infection in plants. Annu. Rev. Plant Physiol. 35:243-275.

Digonnet, C., Martinez, Y., Denancé, N., Chasseray, M., Dabos, P., Ranocha, P., Marco, Y., Jauneau, A., and Goffner, D. 2012. Deciphering the route of Ralstonia solanacearum colonization in Arabidopsis thaliana roots during a compatible interaction: Focus at the plant cell wall. Planta 236:1419-1431.

Dong, Y., Burch-Smith, T. M., Liu, Y., Mamillapalli, P., and Dinesh-Kumar, S. P. 2007. A ligation-independent cloning tobacco rattle virus vector for high-throughput virus-induced gene silencing identifies roles for NbMADS4-1 and -2 in floral development. Plant Physiol. 145:1161-1170.

Elias, J. E., and Gygi, S. P. 2007. Target-decoy search strategy for increased confidence in large-scale protein identifications by mass spectrometry. Nat. Methods 4:207-214.

Elphinstone, J. G. 2005. The current bacterial wilt situation: A global overview. Pages 9-28 in: Bacterial Wilt: The Disease and the Ralstonia 
solanacearum Species Complex. C. Allen, P. Prior, and A. C. Hayward, eds. American Phytopathological Society, St. Paul, MN, U.S.A.

Etchebar, C., Trigalet-Demery, D., van Gijsegem, F., Vasse, J., and Trigalet, A. 1998. Xylem colonization by an $\mathrm{HrcV}^{-}$mutant of Ralstonia solanacearum is a key factor for the efficient biological control of tomato bacterial wilt. Mol. Plant-Microbe Interact. 11:869-877.

Ferreira, V., Pianzzola, M. J., Vilaró, F. L., Galván, G. A., Tondo, M. L., Rodriguez, M. V., Orellano, E. G., Valls, M., and Siri, M. I. 2017. Interspecific potato breeding lines display differential colonization patterns and induced defense responses after Ralstonia solanacearum Infection. Front. Plant Sci. 8:1424.

Flores-Cruz, Z., and Allen, C. 2009. Ralstonia solanacearum encounters an oxidative environment during tomato infection. Mol. Plant-Microbe Interact. 22:773-782.

Frey, P., Prior, P., Marie, C., Kotoujansky, A., Trigalet-Demery, D., and Trigalet, A. 1994. Hrp mutants of Pseudomonas solanacearum as potential biocontrol agents of tomato bacterial wilt. Appl. Environ. Microbiol. 60:3175-3181.

Gafken, P. R., and Lampe, P. D. 2006. Methodologies for characterizing phosphoproteins by mass spectrometry. Cell Commun. Adhes. 13: 249-262.

Garg, R. P., Huang, J., Yindeeyoungyeon, W., Denny, T. P., and Schell, M. A. 2000. Multicomponent transcriptional regulation at the complex promoter of the exopolysaccharide I biosynthetic operon of Ralstonia solanacearum. J. Bacteriol. 182:6659-6666.

Genin, S. 2010. Molecular traits controlling host range and adaptation to plants in Ralstonia solanacearum. New Phytol. 187:920-928.

Genin, S., and Denny, T. P. 2012. Pathogenomics of the Ralstonia solanacearum species complex. Annu. Rev. Phytopathol. 50:67-89.

Grene, R. 2002. Oxidative stress and acclimation mechanisms in plants. Arabidopsis Book 1:e0036.

Holsters, M., Silva, B., Van Vliet, F., Genetello, C., De Block, M., Dhaese, P., Depicker, A., Inzé, D., Engler, G., Villarroel, R., Van Montagu, M., and Schell, J. 1980. The functional organization of the nopaline A. tumefaciens plasmid pTiC58. Plasmid 3:212-230.

Imlay, J. A. 2008. Cellular defenses against superoxide and hydrogen peroxide. Annu. Rev. Biochem. 77:755-776.

Jacob, F., Vernaldi, S., and Maekawa, T. 2013. Evolution and conservation of plant NLR functions. Front. Immunol. 4:297.

Jacobs, J. M., Milling, A., Mitra, R. M., Hogan, C. S., Ailloud, F., Prior, P., and Allen, C. 2013. Ralstonia solanacearum requires PopS, an ancient AvrE-family effector, for virulence and to overcome salicylic acid-mediated defenses during tomato pathogenesis. MBio 4:e00875-13.

Jamet, A., Sigaud, S., Van de Sype, G., Puppo, A., and Hérouart, D. 2003. Expression of the bacterial catalase genes during Sinorhizobium meliloti-Medicago sativa symbiosis and their crucial role during the infection process. Mol. Plant-Microbe Interact. 16:217-225.

Jones, J. D., and Dangl, J. L. 2006. The plant immune system. Nature 444: 323-329.

Joo, J. H., Bae, Y. S., and Lee, J. S. 2001. Role of auxin-induced reactive oxygen species in root gravitropism. Plant Physiol. 126:1055-1060.

Kadota, Y., Macho, A. P., and Zipfel, C. 2016. Immunoprecipitation of plasma membrane receptor-like kinases for identification of phosphorylation sites and associated proteins. Methods Mol. Biol. 1363: 133-144.

Landry, D., González-Fuente, M., Deslandes, L., and Peeters, N. 2020. The large, diverse, and robust arsenal of Ralstonia solanacearum type III effectors and their in planta functions. Mol. Plant Pathol. 21:1377-1388.

Lee, H. J., Mochizuki, N., Masuda, T., and Buckhout, T. J. 2012. Disrupting the bimolecular binding of the haem-binding protein 5 (AtHBP5) to haem oxygenase 1 (HY1) leads to oxidative stress in Arabidopsis. J. Exp. Bot. 63:5967-5978.

Liu, Y., Yan, J., Qin, Q., Zhang, J., Chen, Y., Zhao, L., He, K., and Hou, S. 2020. Type one protein phosphatases (TOPPs) contribute to the plant defense response in Arabidopsis. J. Integr. Plant Biol. 62:360-377.

Livak, K. J., and Schmittgen, T. D. 2001. Analysis of relative gene expression data using real-time quantitative PCR and the $2^{-\Delta \Delta C T}$ method. Methods 25:402-408

Lonjon, F., Turner, M., Henry, C., Rengel, D., Lohou, D., van de Kerkhove, Q., Cazalé, A. C., Peeters, N., Genin, S., and Vailleau, F. 2016. Comparative secretome analysis of Ralstonia solanacearum type 3 secretion-associated mutants reveals a fine control of effector delivery, essential for bacterial pathogenicity. Mol. Cell. Proteomics 15: 598-613.

Lu, H., Lema A, S., Planas-Marquès, M., Alonso-Díaz, A., Valls, M., and Coll, N. S. 2018. Type III secretion-dependent and -independent phenotypes caused by Ralstonia solanacearum in Arabidopsis roots Mol. Plant-Microbe Interact. 31:175-184.

Ma, J., Chen, T., Wu, S., Yang, C., Bai, M., Shu, K., Li, K., Zhang, G., Jin, Z., He, F., Hermjakob, H., and Zhu, Y. 2019. iProX: An integrated proteome resource. Nucleic Acids Res. 47:D1211-D1217.

Macho, A. P. 2016. Subversion of plant cellular functions by bacterial type-III effectors: Beyond suppression of immunity. New Phytol. 201:51-57.

Mandal, S., Das, R. K., and Mishra, S. 2011. Differential occurrence of oxidative burst and antioxidative mechanism in compatible and incompatible interactions of Solanum lycopersicum and Ralstonia solanacearum. Plant Physiol. Biochem. 49:117-123.

Mansfield, J., Genin, S., Magori, S., Citovsky, V., Sriariyanum, M., Ronald, P., Dow, M., Verdier, V., Beer, S. V., Machado, M. A., Toth, I., Salmond, G., and Foster, G. D. 2012. Top 10 plant pathogenic bacteria in molecular plant pathology. Mol. Plant Pathol. 13:614-629.

McAvoy, T., Freeman, J. H., Rideout, S. L., Olson, S. M., and Paret, M. L. 2012. Evaluation of grafting using hybrid rootstocks for management of bacterial wilt in field tomato production. HortScience 47:621-625.

McGarvey, J. A., Denny, T. P., and Schell, M. A. 1999. Spatial-temporal and quantitative analysis of growth and EPS I production by Ralstonia solanacearum in resistant and susceptible tomato cultivars. Phytopathology 89:1233-1239.

Mehdy, M. C. 1994. Active oxygen species in plant defense against pathogens. Plant Physiol. 105:467-472.

Miller, R. A., and Britigan, B. E. 1997. Role of oxidants in microbial pathophysiology. Clin. Microbiol. Rev. 10:1-18.

Mori, I. C., and Schroeder, J. I. 2004. Reactive oxygen species activation of plant $\mathrm{Ca}^{2+}$ channels. A signaling mechanism in polar growth, hormone transduction, stress signaling, and hypothetically mechanotransduction. Plant Physiol. 135:702-708.

Nicot, N., Hausman, J. F., Hoffmann, L., and Evers, D. 2005. Housekeeping gene selection for real-time RT-PCR normalization in potato during biotic and abiotic stress. J. Exp. Bot. 56:2907-2914.

Ohkura, S. I., Hori, M., Saitoh, K., Okuzawa, T., Okamoto, I., Furukawa, N., and Shimizu-Ibuka, A. 2018. Structural and functional analysis of miraculin-like protein from Vitis vinifera. Biochim. Biophys. Acta. Proteins Proteomics 1866:1125-1130.

Pecinka, A., Rosa, M., Schikora, A., Berlinger, M., Hirt, H., Luschnig, C., and Mittelsten Scheid, O. 2009. Transgenerational stress memory is not a general response in Arabidopsis. PLoS One 4:e5202.

Peeters, N., Carrère, S., Anisimova, M., Plener, L., Cazalé, A. C., and Genin, S. 2013. Repertoire, unified nomenclature and evolution of the type III effector gene set in the Ralstonia solanacearum species complex. BMC Genomics 14:859.

Poueymiro, M., Cazalé, A. C., François, J. M., Parrou, J. L., Peeters, N., and Genin, S. 2014. A Ralstonia solanacearum type III effector directs the production of the plant signal metabolite trehalose-6-phosphate. MBio 5: e02065-14.

Puigvert, M., Guarischi-Sousa, R., Zuluaga, P., Coll, N. S., Macho, A. P., Setubal, J. C., and Valls, M. 2017. Transcriptomes of Ralstonia solanacearum during root colonization of Solanum commersonii. Front. Plant Sci. 8:370.

Ross, P. L., Huang, Y. N., Marchese, J. M., Williamson, B., Parker, K., Hattan, S., Khainovski, N., Pillai, S., Dey, S., Daniels, S., Purkayastha, S., Juhasz, P., Martin, S., Bartlet-Jones, M., He, F., Jacobson, A., and Pappin, D. J. 2004. Multiplexed protein quantitation in Saccharomyces cerevisiae using amine-reactive isobaric tagging reagents. Mol. Cell. Proteomics 3:1154-1169.

Sang, Y., and Macho, A. P. 2017. Analysis of PAMP-triggered ROS burst in plant immunity. Pages 143-153 in: Plant Pattern Recognition Receptors: Methods and Protocols. L. Shan and P. He, eds. Springer New York, New York, NY, U.S.A.

Torres, M. A., and Dangl, J. L. 2005. Functions of the respiratory burst oxidase in biotic interactions, abiotic stress and development. Curr. Opin. Plant Biol. 8:397-403.

Urvalek, A. M., Osei-Sarfo, K., Tang, X. H., Zhang, T., Scognamiglio, T., and Gudas, L. J. 2015. Identification of ethanol and 4-nitroquinoline-1oxide induced epigenetic and oxidative stress markers during oral cavity carcinogenesis. Alcohol. Clin. Exp. Res. 39:1360-1372.

Van Gijsegem, F., Genin, S., and Boucher, C. 1993. Conservation of secretion pathways for pathogenicity determinants of plant and animal bacteria. Trends Microbiol. 1:175-180.

Vasse, J., Genin, S., Frey, P., Boucher, C., and Brito, B. 2000. The hrpB and hrpG regulatory genes of Ralstonia solanacearum are required for different stages of the tomato root infection process. Mol. Plant-Microbe Interact. 13:259-267. 
Wang, Y., Yu, B., Zhao, J., Guo, J., Li, Y., Han, S., Huang, L., Du, Y., Hong, Y., Tang, D., and Liu, Y. 2013. Autophagy contributes to leaf starch degradation. Plant Cell 25:1383-1399.

Wiśniewski, J. R., Zougman, A., Nagaraj, N., and Mann, M. 2009. Universal sample preparation method for proteome analysis. Nat. Methods 6:359-362.

Xu, F., Copeland, C., and Li, X. 2015. Protein immunoprecipitation using Nicotiana benthamiana transient expression system. Bio-Protocol 5:e1520.

Yamchi, A., Ben, C., Rossignol, M., Zareie, S. R., Mirlohi, A., SayedTabatabaei, B. E., Pichereaux, C., Sarrafi, A., Rickauer, M., and Gentzbittel, L. 2018. Proteomics analysis of Medicago truncatula response to infection by the phytopathogenic bacterium Ralstonia solanacearum points to jasmonate and salicylate defence pathways. Cell. Microbiol. 20:e12796.

Yu, G., Xian, L., Xue, H., Yu, W., Rufian, J. S., Sang, Y., Morcillo, R. J. L., Wang, Y., and Macho, A. P. 2020. A bacterial effector protein prevents
MAPK-mediated phosphorylation of SGT1 to suppress plant immunity. PLoS Pathog. 16:e1008933.

Zheng, X., Li, X., Wang, B., Cheng, D., Li, Y., Li, W., Huang, M., Tan, X., Zhao, G., Song, B., Macho, A. P., Chen, H., and Xie, C. 2019. A systematic screen of conserved Ralstonia solanacearum effectors reveals the role of RipAB, a nuclear-localized effector that suppresses immune responses in potato. Mol. Plant Pathol. 20:547-561.

Zolobowska, L., and Van Gijsegem, F. 2006. Induction of lateral root structure formation on petunia roots: A novel effect of GMI1000 Ralstonia solanacearum infection impaired in Hrp mutants. Mol. PlantMicrobe Interact. 19:597-606.

Zuluaga, A. P., Solé, M., Lu, H., Góngora-Castillo, E., Vaillancourt, B., Coll, N., Buell, C. R., and Valls, M. 2015. Transcriptome responses to Ralstonia solanacearum infection in the roots of the wild potato Solanum commersonii. BMC Genomics 16:246. 